\title{
Typhoon damage on a shallow mesophotic reef in Okinawa, Japan
}

Little is known about effects of large storm systems on mesophotic reefs. This study reports on how Typhoon 17 (Jelawat) affected Ryugu Reef on Okinawa-jima, Japan in September 2012. Benthic communities were surveyed before and after the typhoon using line intercept transect method. Comparison of the benthic assemblages showed highly significant differences in coral coverage at depths of 25-32 m before and after Typhoon 17. A large deep stand of Pachyseris foliosa was apparently less resistant to the storm than the shallower high diversity area of this reef. Contradictory to common perception, this research shows that large foliose corals at deeper depths are just as susceptible to typhoon damage as shallower branching corals. However, descriptive functional group analyses resulted in only minor changes after the disturbance, suggesting the high likelihood of recovery and the high resilience capacity of this mesophotic reef. 


\section{Typhoon damage on a shallow mesophotic reef in Okinawa, Japan}

2 KRISTINE.N. WHITE ${ }^{a^{*}}$, TAKU OHARA $^{\mathrm{b}, \mathrm{c}}$, TAKUMA FUJII $^{\mathrm{b}}$, IORI KAWAMURA $^{\mathrm{b}}$, MASARU

3 MIZUYAMA $^{\mathrm{b}}$, JAVIER MONTENEGRO $^{\mathrm{b}}$, HARUKA SHIKIBA $^{\mathrm{b}}$, TOHRU NARUSE $^{\mathrm{d}}$, TY

$4 \quad$ McCLELLAND $^{\mathrm{b}}$, VIANNEY DENIS ${ }^{\mathrm{e}}$, JAMES D. REIMER ${ }^{\mathrm{b}}$

5 anniversity of Maryland University College, Asia Division, Camp Foster Education Center, Unit 6 35042, FPO AP 96373-5042

7 braduate School of Engineering and Science, University of the Ryukyus, 1 Senbaru, Nishihara,

8 Okinawa 903-0213, Japan

$9 \quad{ }^{\mathrm{c} B e n t h o s ~ D i v e r s, ~} 475$ Seragaki, Onna, Okinawa 904-0404, Japan

10 Tropical Biosphere Research Center, Iriomote Station, University of the Ryukyus, Uehara 870,

11 Taketomi, Okinawa 907-1541, Japan

$12{ }^{\mathrm{e} B i o d i v e r s i t y ~ R e s e a r c h ~ C e n t e r, ~ A c a d e m i a ~ S i n i c a, ~ T a i p e i ~ 115, ~ T a i w a n ~}$

13 *Corresponding Author e-mail: kristine.white@,faculty.umuc.edu; phone: +81-80-6493-1946;

14 fax: $+81-98-895-8577$

15 Keywords: mesophotic, coral reef, typhoon damage, Japan, succession 
Introduction

Typhoon damage from direct physical disturbances, turbidity, sedimentation, and salinity changes can be destructive to shallow coral reefs and has been well studied (Van Woesik, Ayling \& Mapstone, 1991; Harmelin-Vivien, 1994; Ninio et al., 2000; Cheal et al., 2002; Hongo, Kawamata \& Goto, 2012). Declines in coral cover on shallow reefs ( $<25 \mathrm{~m}$ in depth) has been documented, specifically in genera such as Acropora, Montastraea, Porites, Agaracia, Diploria, Millepora, Siderastrea, Pocillopora, Pachyseris, Montipora, and Merulina (Harmelin-Vivien, 1994; Van Woesik, De Vantier \& Glazebrook, 1995; Fabricius et al., 2008). Although massive corals such as Montipora, Montastraea, Siderastrea, and Diploria can be overturned during typhoons, they are often the most resistant to storms and therefore tend to dominate or increase in cover after a disturbance (Harmelin-Vivien, 1994; Fabricius et al., 2008; Hongo, Kawamata \& Goto, 2012). Increase in cover of genera Porites, Montipora, and Lobophyllia, unattached fungiids and even Acropora species with high regeneration efficiencies have been documented after disturbances (Harmelin-Vivien, 1994; Van Woesik, De Vantier \& Glazebrook, 1995; Fabricius et al., 2008; Kuo et al., 2010).

Recent observational data of a mesophotic reef (35-40 m) near Kume-jima, Okinawa, Japan before and after a typhoon reported that newly broken Acropora pieces fused to new branches, producing clones, and the reef made a quick recovery after typhoon damage (Fujita, Kimura, \& Atsuo, 2012). deeper reefs (Randall \& Eldredge, 1977; Woodley et al., 1981; Walsh, 1983; Pfeffer \& Tribble, 1985; Harmelin-Vivien \& Laboute, 1986; Van Woesik, Ayling \& Mapstone, 1991). In general, reefs at depths greater than 25 meters appear to be less affected by tropical cyclones than shallower reefs (Harmelin-Vivien, 1994; Bongaerts et al., 2011; Bridge \& Guinotte, 2012). 
41 colonies dislodged from shallower areas. However, as reported in Harmelin-Vivien (1994),

42 tropical cyclone induced coral destruction was observed to depths of $25 \mathrm{~m}$ in Belize (Highsmith,

43 Riggs, \& D’Antonio, 1980), to $30 \mathrm{~m}$ on the Great Barrier Reef (Van Woesik, Ayling \& Mapstone,

44 1991), to $30 \mathrm{~m}$ in Guam and Hawaii (Walsh, 1983), to $50 \mathrm{~m}$ in Jamaica (Woodley et al., 1981), to

$4550 \mathrm{~m}$ in Hawaii (Pfeffer \& Tribble, 1985), to 50-65 $\mathrm{m}$ on the Great Barrier Reef (Bongaerts et al.,

46 2013), and to 90-100 m in French Polynesia (Laboute, 1985; Harmelin-Vivien \& Laboute, 1986).

47 Bridge and Guinotte (2012) concluded that although depth does have an impact on coral

48 community survival, rugosity and angle of slope play large roles in the protection of species on a

49 reef. Large communities of of broadcast spawning species are important to the recovery of reefs

50 and are more likely to survive in deeper waters than in shallower waters during a typhoon (Madin

51 \& Connolly, 2006; Bridge et al., 2012), and recruitment of coral larvae is likely the most effective

52 method of recovery for disturbed reefs (Harmelin-Vivien, 1994).

53 Typhoon 17 (Jelawat) struck the west coast of Okinawa-jima Island on 29 September

542012 (Fig. 1), heading from the southwest to the northeast with a general wind direction of

55 northwest. The Japan Meteorological Agency (JMA) and the United States Navy Joint Typhoon

56 Warning Center (JTW) documented this record-breaking typhoon as the third strongest typhoon

57 to hit Okinawa-jima Island since weather radar observations were started in 1954 with maximum

58 wave heights of $12 \mathrm{~m}$. The Okinawa Meteorological Observatory (OMO) recorded the following

59 maximum measurements for Typhoon 17 at the northern end of Okinawa-jima Island (Nago

60 Meteorological Station): $32.2 \mathrm{~m} / \mathrm{s}$ sustained winds, $57.4 \mathrm{~m} / \mathrm{s}$ wind gusts, $947.4 \mathrm{hPa}$ atmospheric

61 pressure.

62 Recently, Ohara et al. (2013) reported on a previously undiscovered shallow mesophotic

63 coral reef in Okinawa, Japan. The Japanese name for this reef is "Ryugu," based on its

64 resemblance to the undersea palace of Ryūjin, the dragon god of the sea. The deeper sections of

65 Ryugu (32-42 m) were reported to be primarily composed of Pachyseris foliosa Veron, 1990, 
66 with shallower sections (25-32 m) showing much higher diversity (Ohara et al., 2013). Little is

67 known about Pachyseris foliosa, although the depth range of this species appears to be deeper

68 than previously reported by Hoeksema, Rogers \& Quibilan in 2008 (25-30 m).

69 This study reports on how Typhoon 17 affected Ryugu Reef with before and after transect

70 data. Objectives of this study include examination of coral communities at different depths and

71 the identification of species and functional groups most affected by typhoons. One hypothesis

72 tested was that shallow mesophotic reefs with large monospecific stands are more resistant to

73 storm damage.

\section{Materials and Methods}

75 Five stations were designated at the Ryugu site (Fig 1). Station 1 was the deepest (42 m)

76 and station 5 the shallowest $(17 \mathrm{~m})$. Stations are shown in Fig. 1 and summarized in Table 1.

77 Temperature was recorded every 30 minutes using temperature loggers (HOBO U22 Temp Pro v2

78 logger, Onset Corp., Massachusetts, U.S.A.) placed approximately 30-50 $\mathrm{cm}$ from the substrate at 79 each station from 12 September 2012 to 10 January 2013.

80 Water motion was estimated at each station (except station 1) by the dissolution of plaster

81 balls. Plaster balls (10.5 cm diameter) were made following Komatsu and Kawai (1992). The

82 balls were set approximately $50 \mathrm{~cm}$ above the substrate at stations 2-5 on 11 January 2013 and

83 removed on 16 January 2013. Water speeds for each station were calculated following the

84 equations provided in Yokoyama, Inoue \& Abo (2004).

85 Ten meter line transects were surveyed both before (17 April 2012 and 11-12 September

86 2012) and after (14 December 2012) Typhoon 17 at locations near stations 2 (7 transects before, 9

87 transects after) and 3 (10 transects before, 8 transects after). Based on the amount of data

88 available, only stations 2 and 3 were included in analyses. For each line transect, a 10 meter tape

89 measure was laid out along a constant dedpth contour and overlapping photographs or video was 
taken along the line. Photographs or videos taken along the transects were used to report the total

91 distance occupied by each operational taxonomic unit (OTU) identified. When feasible, OTUs

92 were identified to species level following Hoeksema (1989) and Gittenberger, Reignen \&

93 Hoeksema (2011) for Fungiidae and Veron (2000) for other species.

94 Community data were analyzed using PRIMER 6 statistical software in order to find

95 differences in coral communities before and after the typhoon (Clarke and Warwick, 2001). All

96 percent cover data were square-root transformed prior to analysis to moderately down-weight the

97 importance of large space occupying operational taxonomic units (OTU). Bray-Curtis similarity

98 matrices were calculated at stations 2 and 3. A one-way analysis of similarities test (ANOSIM)

99 was performed to determine the difference and magnitude of difference in the assemblages before

100 and after Typhoon 17. Non-Metric Multidimensional scaling (nMDS) was used to visualize

101 multivariate patterns on the basis of the Bray-Curtis matrix. Bubble plot (square-root transformed 102 cover data) was added to the plots to visualize variation in relevant OTUs. Each circle in figure 4

103 displays relative abundance of livecoral species (based on square root transformed data of the

104 species' occurrence along each transect). Finally, the percentage contributions of each benthic

105 grouping for observed differences between locations were assessed with the SIMPER routine.

106 To assess potential changes in the functionality of the coral community after the typhoon

107 coral taxa were classified into functional groups according to the shapes of the colonies following

108 Denis et al. (2013). Each OTU was assigned to one or more of eight functional groups: massive,

109 encrusting, foliose, columnar, plate-like, bushy, arborescent, and unattached (Supplementary

110 Table 1). These were defined by each colony's growth form as described in Veron (2000),

111 Wallace (1999) and by visual observation. Functional composition of the coral assemblages were

112 calculated based on the relative abundance of coral OTU and plot for stations 2 and 3 before and

113 after the typhoon. 
Temperature sensors showed that the temperature was typically $0.1-0.2$ degrees lower at station 5 (shallowest station) than at any of the other stations, although the temperature appeared to fluctuate the most at this station. Temperature drops were observed at all stations during and

118 directly after typhoons, with the largest decrease in temperature at station $1\left(20.9^{\circ} \mathrm{C}\right.$ after Typhoon 17) (Fig. 2). Based on plaster ball weight loss, station 2 had the lowest amount of water movement compared to the other stations. The weight loss of each plaster ball and water speed 121 for each station were as follows: Station 2: lost $254 \mathrm{~g}, 9.2 \mathrm{~cm} / \mathrm{s}$; Station 3: lost $284 \mathrm{~g}, 11.2 \mathrm{~cm} / \mathrm{s}$; 122 Station 4: lost $292 \mathrm{~g}, 11.7 \mathrm{~cm} / \mathrm{s}$; Station 5: lost $294 \mathrm{~g}, 12.5 \mathrm{~cm} / \mathrm{s}$.

Supplementary table 1 lists all OTUs documented on transects and their percent cover change before and after Typhoon 17. Live coral cover decreased and coral rubble increased by $33.3 \%$ at station 2 and by $11.4 \%$ at station 3 after Typhoon 17. Figure 3 shows before and after images at stations 2 and 3.

Composition of the benthic communities before and after Typhoon 17 (Fig. 4) presented a significant difference at both station 2 (ANOSIM test, $\mathrm{R}=0.572, \mathrm{p}=0.001$ ) and station 3 (ANOSIM test, $\mathrm{R}=0.24, \mathrm{p}=0.009$ ). At station 2 , the change in the occurrence of coral rubble on 130 the transects contributed the most to this difference (Simper-test, 33.0\% - Fig. 4), followed by the 131 coverage of Lithophyllon repanda (12.7\%), Pachyseris foliosa (11.6\%), then Galaxea sp. 1

$132(11.2 \%)$. At station 3, every OTU contributed to $<10 \%$ of the difference observed. Change in the 133 occurrence of coral rubble contributed to only $6 \%$ of this difference (Fig. 4). Interestingly, the 134 difference observed at station 3 was not significant $(R=0.07, p=0.137)$ when the effects of the 135 dominant OTU were not reduced using square root transformation. Functionality of the coral 136 communities (Fig. 5) at both stations seems only slightly affected by the typhoon. Among the 137 major differences observed at station 2, the encrusting group decreased by $8 \%$, while the foliose 138 group increased by $15 \%$. At station 3, bushy (8\%), columnar (6\%) and plate-like (3\%) groups 
139 suffered the most from the path of the typhoon while encrusting (7\%) and foliose (11\%) corals

140 were more resistant to this disturbance.

\section{Discussion}

142 Typhoon 17 resulted in highly significant changes to the live coral abundance at Ryugu

143 stations 2 and 3. The depth of this reef does not appear to have sheltered corals from drastic

144 damage with notable increases in coral rubble in many of the study areas. Most interestingly, $P$.

145 foliosa was among those species most affected by Typhoon 17. Apparently more diverse and

146 complex communities, such as at station 3, are more resistant to typhoons in terms of

147 survivability and functional group distribution, perhaps due to the lower impact on individual

148 species. Based on SIMPER tests, there were many small differences in diverse OTUs at station 3

149 compared to station 2 , where only 4 OTUs contributed to $70 \%$ of the typhoon effects. Station 2 ,

150 primarily composed of $P$. foliosa, was heavily impacted by this storm, despite the fact that it was

151 deeper than station 3, suggesting that the foliose structure of $P$. foliosa is vulnerable to physical

152 disturbances. The large monospecific stand found here is also in a more stable environment,

153 likely making it more sensitive to disturbance (Hughes, 1989; Rogers, 1992, 1993; Harmelin-

154 Vivien, 1994). Therefore, our hypothesis that shallow mesophotic reefs with large monospecific

155 stands are more resistant to storm damage is rejected.

156 Consistent with previous shallow water typhoon damage studies (Harmelin-Vivien,

157 1994; Van Woesik, De Vantier \& Glazebrook, 1995; Fabricius et al., 2008; Kuo et al., 2010)

158 corals in the genus Acropora were strongly affected and were mostly dead at Ryugu after

159 Typhoon 17 whereas unattached Fungiidae corals were mostly healthy. The fungiid corals may

160 have been hidden under other living corals and after Typhoon 17 became more visible with the

161 other corals having been damaged. Away from the transect locations; however, several Fungiidae

162 corals were completely buried by newly generated Acropora rubble and other branching coral 
163 rubble. Accordingly, despite minor changes in the functionality of the coral community observed

164 before and after Typhoon 17, the groups the most affected at station 3 were the bushy, columnar 165 and plate-like corals. At station 2, the dominance of $P$. foliosa may have masked any differences.

166 Most damaged colonies of $P$. foliosa were still alive after Typhoon 17, suggesting that species

167 composition of this area may not change. This opposes the common idea that only massive corals

168 would remain after disturbance (Harmelin-Vivien, 1994), suggesting a strong potential for the

169 recovery and resilience of Ryugu Reef. Pachyseris species are typically gonochoric spawners that 170 are most likely unable to fuse and create clones (Richmond and Hunter, 1990). If Pachyseris

171 species reproduce only by spawning, Pachyseris-dominated reefs such as Ryugu should have a

172 much slower recovery rate than Acropora-dominated reefs such as the one found near Kume-

173 jima. However, recruitment of coral larvae may allow this reef to recover relatively quickly.

174 During this study, new P. foliosa polyps were observed growing two to three months after

175 Typhoon 17, suggesting that the Pachyseris portion of the reef had already started to recover

176 from the damage it incurred.

177 Based on plaster ball data, Ryugu is a fairly calm reef and the lower currents at station 2

178 may be due to less tides or wave impacts, and is worth investigating further in future studies. The

179 lower temperature observed during Typhoon 17 at station 1 (42 m) may be due to upwelling or

180 thermal averaging due to wind driven vertical mixing with deeper cooler water that was enhanced

181 by the onset of the typhoon, as seen during other large storms. Figure 2 shows large changes in 182 temperature on 18 September (drop to $26.0^{\circ} \mathrm{C}$ ) and 30 September (drop to $20.9^{\circ} \mathrm{C}$ ), both of which 183 correspond with large typhoon systems (Fig. 1; Typhoons 16 and 17, respectively).

184 Many studies have found that increasing sea surface temperatures and global climate

185 change have and will continue to cause increases in typhoon frequency, power dissipation, and

186 storm intensity (Emanuel, 2005; Trenberth, 2005; Webster et al., 2005; Emanuel, Sundararajan \&

187 Williams, 2008; Tu et al., 2009). Tu et al. (2009) have documented a northward shift in typhoon 
tracks in the western North Pacific-East Asia region with an increase in typhoon frequency in the

189 Taiwan/East China Sea region (3.3 per year from 1970-1999; 5.7 per year from 2000-2006).

190 Emanuel (2005) documented an increase in destructiveness of cyclones since the 1970s and has

191 predicted a continued increase with global climate change. Global climate change is expected to

192 bring larger and stronger typhoons to Okinawa, which will likely affect the survivability of some

193 coral populations. A potential increase in storms makes it even more important to understand their

194 effect on mesophotic reefs, which have been thought to act as refugia for many marine organisms

195 during disturbances on shallow reefs. This study has shown that despite their depth, shallow

196 mesophotic reefs may also be strongly affected by disturbances. It is, therefore, critical to

197 document the succession of this reef after disturbances such as Typhoon 17 to understand its

198 resilience and the role that mesophotic reefs may play in the future of coral reefs.

\section{Acknowledgements}

200 Thanks go to the boat captain, Tokunobu Toyama and diving staff, Sakiko Kawabata and Yoko

201 Fudesaka, for their assistance during transect surveys. V. Denis is the recipient of a Post-Doctoral

202 fellowship by the National Science Council of Taiwan. J.D. Reimer was funded by the Rising

203 Star Program, and International Research Hub Project for Climate Change and Coral Reef/Island

204 Dynamics, both at the University of the Ryukyus. 
206

207

208

209

210

211

212

213

214

215

216

217

218

219

220

221

222

223

224

225

226

227

228

229

230

231

232

233

234

235

236

237

238

239

240

241

242

243

244

245

246

247

248

249

250

251

252

Bongaerts P, Bridge TCL, Kline DI, Muir PR, Wallace CC, Beaman RJ, Hoegh-Guldberg O. 2011. Mesophotic coral ecosystems on the walls of Coral Sea atolls. Coral Reefs 30: 335 [doi:10.1007/s00338-011-0725-7].

Bongaerts P, Muir P, Englebert N, Bridge TCL, Hoegh-Guldberg O. 2013. Cyclone damage at mesophotuc depths on Myrmidon Reef (GBR). Coral Reefs [doi:10.1007/s00338-013$1052-\mathrm{y}]$.

Bridge T, Guinotte J. 2012. Mesophotic coral reef ecosystems in the Great Barrier Reef world heritage area: their potential distribution and possible role as refugia from disturbance. Great Barrier Reef Marine Park Authority, Townsville, Australia.

Cheal AJ, Coleman G, Delean S, Miller I, Osborne K, Sweatman H. 2002. Responses of coral and fish assemblages to a severe but short-lived tropical cyclone on the Great Barrier Reef, Australia. Coral Reefs 21: 131-142 [doi: 10.1007/s00338-002-0227-8].

Clarke KR, Warwick RM. 2001. Changes in marine communities: an approach to statistical analysis and interpretation. 2nd Edition. PRIMER-E: Plymouth.

Denis V, Mezaki T, Tanaka K, Kuo CY, De Palmas S, Keshavmurthy S, Chen CA. 2013. Coverage, diversity, and functionality of a high-latitude coral community (Tatsukushi, Shikoku Island, Japan). PloS One 8: e54330.

Emanuel K. 2005. Increasing destructiveness of tropical cyclones over the past 30 years. Nature 436: 686-688.

Emanuel K, Sundararajan R, Williams JGK. 2008. Hurricanes and global warming. Results from downscaling IPCC AR4 simulations. Bulletin of the American Meteorological Society 89: 347-369.

Fabricius KE, De'ath KE, Puotinen ML, Done T, Cooper TF, Burgess SC. 2008. Disturbance gradients on inshore and offshore coral reefs caused by a severe tropical cyclone. Limnology and Oceanography 53: 690-704.

Fujita Y, Kimura T, Atsuo S. 2012. Typhoon damage of large-scaled coral communities dominated by Acropora horrida (Dana, 1846) (Scleractinia: Acroporidae) in the mesophotic zone off Kumejima Island, the Ryukyu Islands, Japan. Okinawa Journal of Biology 50: 61-66.

Gittenberger A, Reignen BT, Hoeksema BW. 2011. A molecularly based phylogeny reconstruction of mushroom corals (Sclearactinia: Fungiidae) with taxonomic consequences and evolutionary implications for life history traits. Contributions to Zoology 80: 107-132.

Harmelin-Vivien ML, Laboute P. 1986. Catastrophic impact of hurricanes on atoll outer reef slopes in the Tuamoto (French Polynesia). Coral Reefs 5: 55-62.

Harmelin-Vivien ML. 1994. The effects of storms and cyclones on coral reefs: A review. Journal of Coastal Research Special Issue 12: 211-231.

Highsmith RC, Riggs AC, D'Antonio CM. 1980. Survival of hurricane-generated coral fragments and a disturbance model of reef calcification/growth rates. Oecologia 7: 207-226.

Hoeksema BW. 1989. Taxonomy, phylogeny and biogeography of mushroom corals (Scleractinia: Fungiidae). Zoologische Verhandelingen (Leiden) 254: 1-295.

Hoeksema B, Rogers A, Quibilan M (2008) Pachyseris foliosa. In: IUCN 2013. IUCN Red List of Threatened Species. Version 2013.1. Available at www.iucnredlist.org (accessed 13 July 2013).

Hongo C, Kawamata H, Goto K. 2012. Catastrophic impact of typhoon waves on coral communities in the Ryukyu Islands under global warming. Journal of Geophysical Research 117: 1-14 [doi:10.1029/2011JG001902]. 
253

254

255

256

257

258

259

260

261

262

263

264

265

266

267

268

269

270

271

272

273

274

275

276

277

278

279

280

281

282

283

284

285

286

287

288

289

290

291

292

293

294

295

296

297

298

299

300

301
Hughes TP. 1989. Community structure and diversity of coral reefs: the role of history. Ecology 70: 275-279.

Komatsu T, Kawai H. 1992. Measurements of time-averaged intensity of water motion with plaster balls. Journal of Oceanography 48: 353-365.

Kuo CY, Meng PJ, Ho PH, Wang JT, Chen JP, Chiu YW, Lin HJ, Chang YC, Fan TY, Chen CA. 2011. Damage to the reefs of Siangjiao Bay Marine Protected Area of Kenting National Park, Southern Taiwan during Typhoon Morakot. Zoological Studies 50:85.

Laboute P. 1985. Evaluation des dégáts causes par les passages des cyclones de 1982-1983 en Polynésie française sur les pentes externs des atolls de Tikehau et de Takapoto (Archipel des Tuamotu). Proceedings Fifth International Coral Reef Symposium 3: 323-329.

Madin JS, Connolly SR. 2006. Ecological consequences of major hydrodynamic disturbances on coral reefs. Nature 444: 477.

National Marine Data and Information Service (NMDIS). n.d. Temperature and Salinity Distributions in the South China Sea. Available at http://www.coi.gov.cn/scs/introduction/wenyan.htm (accessed 30 April 2013).

Ninio R, Meekan M, Done T, Sweatman H. 2000. Temporal patterns in coral assemblages on the Great Barrier Reef from local to large spatial scales. Marine Ecology Progress Series 194: 65-74.

Ohara T, Fujii T, Kawamura I., Mizuyama M, Montenegro J, Shikiba H, White KN, Reimer JD. 2013. First record of a mesophotic Pachyseris foliosa reef from Japan. Marine Biodiversity 43(2): 71-72 [doi: 10.1007/s12526-012-0137-0].

Pfeffer RA, Tribble GW. 1985. Hurricane effect on an aquarium fish fishery in the Hawaiian Islands. Proceedings of the 5th International Coral Reef Symposium 3: 331-336.

Randall RH, Eldredge LG. 1977. Effects of typhoon Pamela on the coral reefs of Guam. Proceedings of the 3rd International Coral Reef Symposium 2: 526-531.

Rogers CS. 1992. A matter of scale: damage from Hurricane Hugo (1989) to U.S. Virgin Islands reefs at the colony, community, and whole reef level. Proceedings of the $7^{\text {th }}$ International Coral Reef Symposium 7: 127-133.

Rogers CS. 1993. Hurricanes and coral reefs: the intermediate disturbance hypothesis revisited. Coral Reefs 12: 127-137.

Trenberth K. 2005. Uncertainty in hurricanes and global warming. Science 308: 1753-1754.

Tu J-Y, Chou C, Chu P-S. 2009. The abrupt shift of typhoon activity in the vicinity of Taiwan and its association with western North Pacific-East Asian climate change. Journal of Climate 22: 3617-3628.

Van Woesik R, Ayling AM, Mapstone B. 1991. Impact of tropical cyclone Ivor on the Great Barrier Reef, Australia. Journal of Coastal Research 7: 551-558.

Van Woesik R, De Vantier LM, Glazebrook JS. 1995. Effects of cyclone 'Joy' on nearshore coral communities of the Great Barrier Reef. Marine Ecology Progress Series 128:261-270.

Veron JEN. 1990. New Scleractinia from Japan and other Indo-West Pacific countries. Galaxea 9: $95-174$.

Veron JEN. 2000. Corals of the world, 3 vols. Townsville: Australian Institute of Marine Science.

Wallace C. 1999. Staghorn corals of the world: a revision of the coral genus Acropora. Collingwood: CSIRO.

Walsh WJ. 1983. Stability of a coral reef fish community following a catastrophic storm. Coral Reefs 2: 49-63.

Webster PJ, Holland GJ, Curry JA, Chang HR. 2005. Changes in tropical cyclone number, duration, and intensity in a warming environment. Science 309: 1844-1846.

Woodley JD, Chornesky EA, Clifford PA, Jackson JBC, Kaufman LS, Knowlton N, Lang JC, Pearson MP, Porter JW, Rooney MC, Rylaarsdam KW, Tunnicliffe VJ, Wahle CM, Wulff 

Hurricane Allen's impact on Jamaican coral reefs. Science 214: 749-755.

304 Yokoyama H, Inoue M, Abo K. 2004. Estimation of the assimilative capacity of fish-farm

305 environments based on the current velocity measured by plaster balls. Aquaculture 240:

306 233-247. 


\section{Figure 1}

Map of Typhoon track and study stations

a)Map showing track of Typhoon 17 (Jelawat) around Okianwa-jima Island with position and b) studied stations of Ryugu Reef. Data on the track indicates date, time, central atmospheric pressure and maximum wind speed at each "X" mark. In b), dotted areas indicate positions of transects.

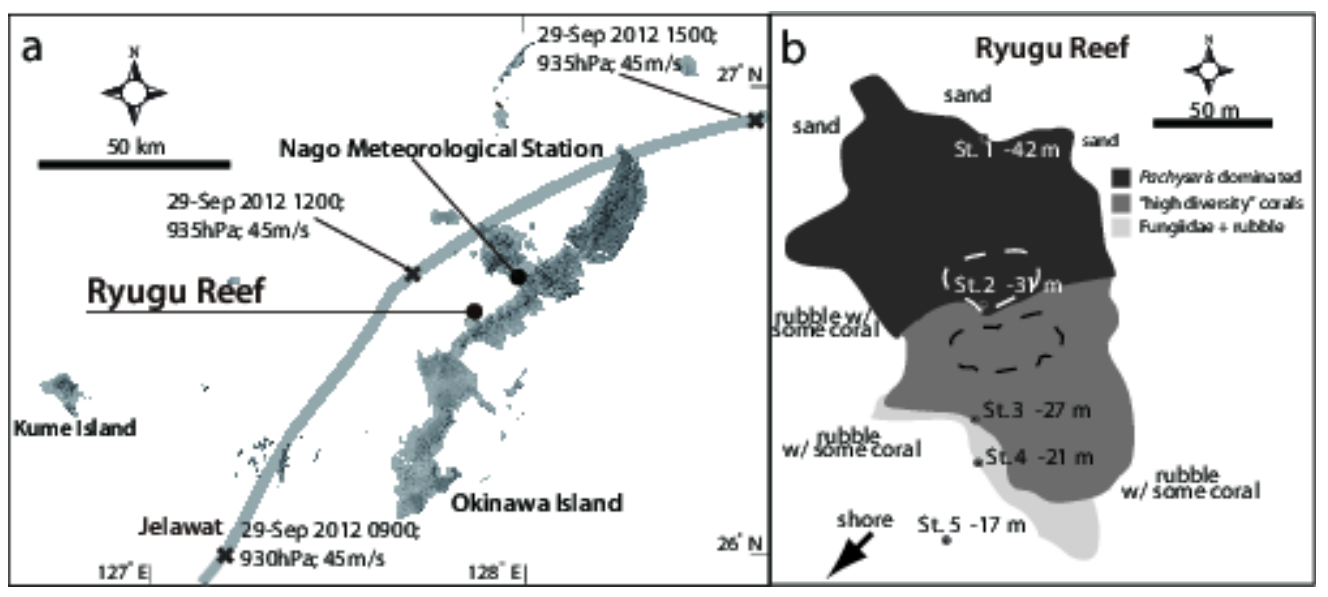




\section{Figure 2}

Daily temperature change for Ryugu Reef

Graph showing daily temperature change for Ryugu Reef, Stations 1-5, 12 September 2012 to 10 January 2013.

Daily Temperature Change

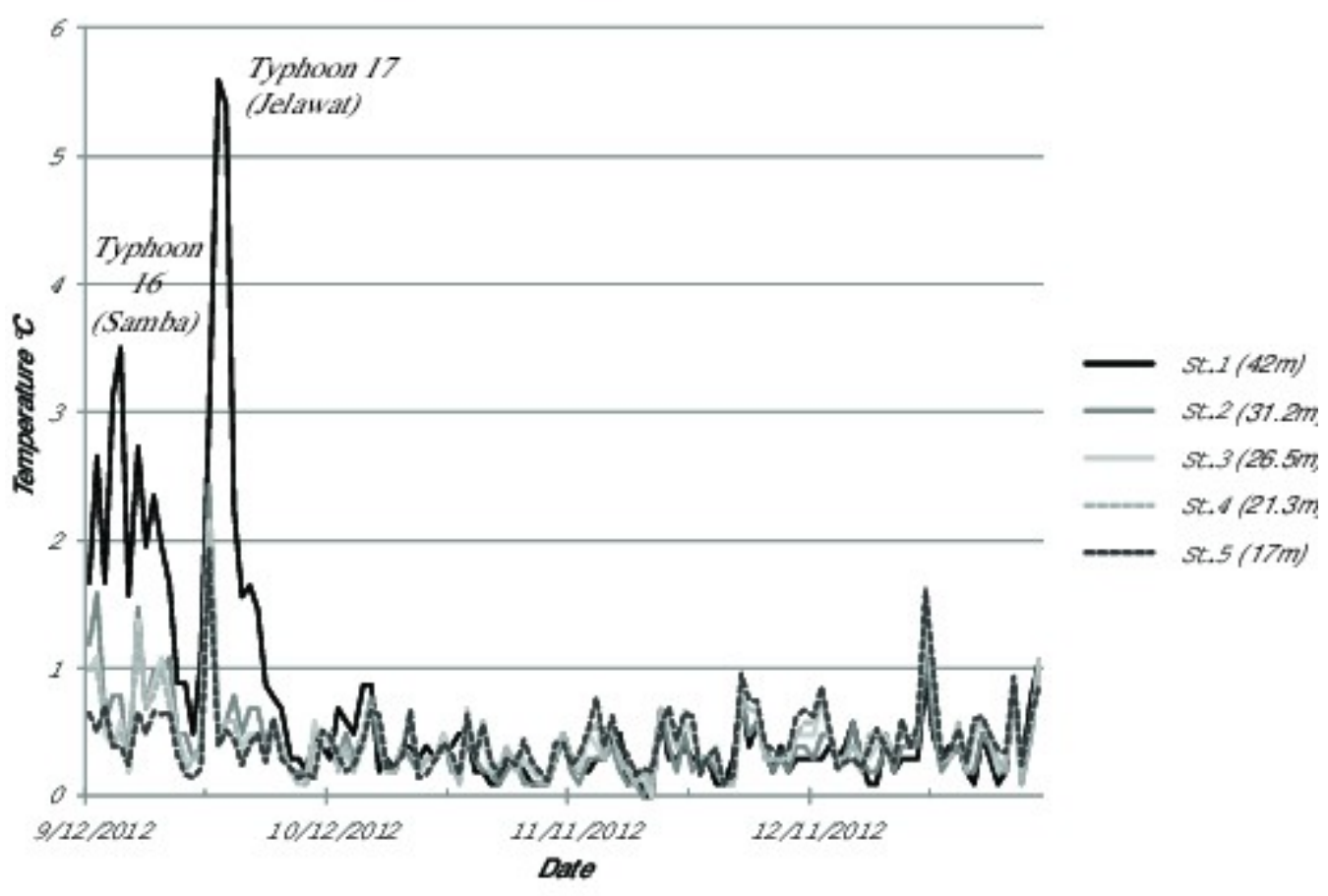




\section{Figure 3}

Ryugu Reef photographs before and after Typhoon 17. Station 2, a) 12 September 2012, b) 01 January 2013; Station 3, c) 12 September 2012, d) 01 January 2013

Ryugu Reef photographs before and after Typhoon 17. Station 2, a) 12 September 2012, b) 01 January 2013; Station 3, c) 12 September 2012, d) 01 January 2013
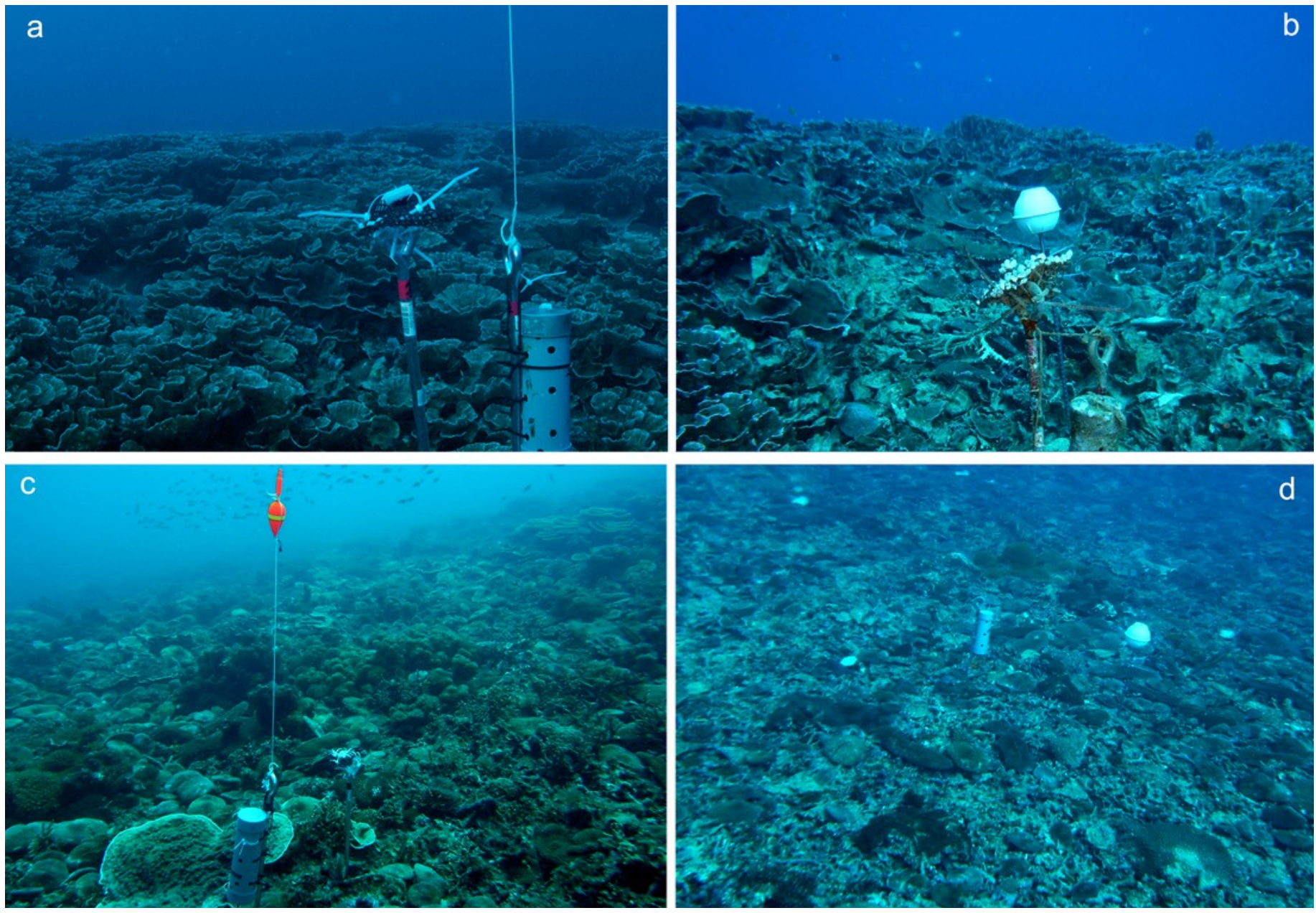


\section{Figure 4}

Non-metric dimensional scaling of the benthic communities at Ryugu Reef

Non-metric dimensional scaling of the benthic communities at Ryugu Reef based on the Bray-Curtis similarities matrices. Each circle in the bubble plot displays relative abundance of live coral or percent cover of coral rubble (based on square root transformed data of the species' occurrence along each transect) a) Station 2: live coral species, b) Station 2: coral rubble, c) Station 3: live coral species, d) Station 3: coral rubble. Red circle: before typhoon, blue circle: after typhoon.

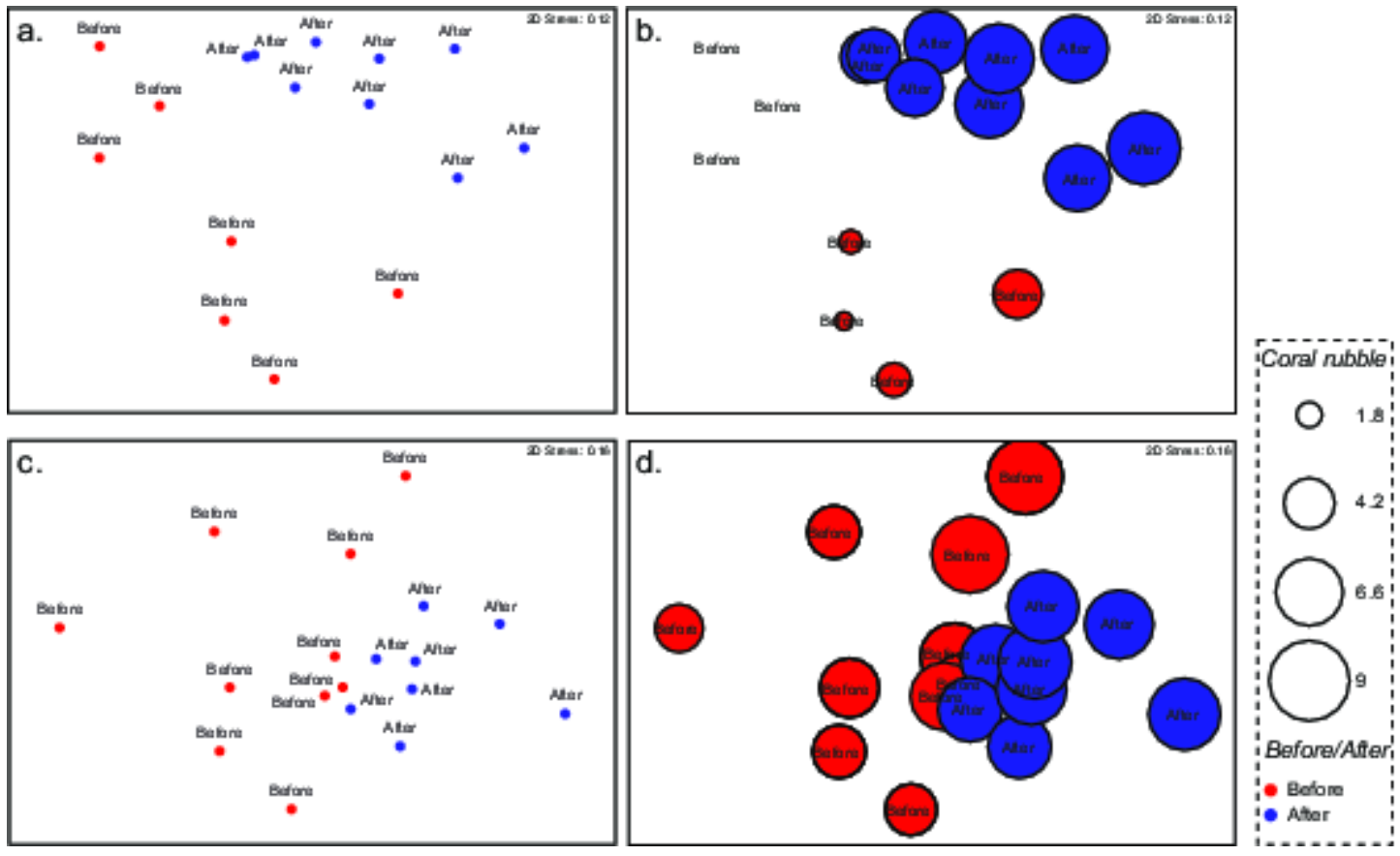




\section{Figure 5}

Functional composition of the coral assemblage before and after Typhoon 17 at Ryugu Reef

Functional composition of the coral assemblage before and after Typhoon 17 at Ryugu Reef, Stations 2 and 3 based on relative abundance of the coral OTUs. Axes represent the relative contribution of each of the 8 functional groups.

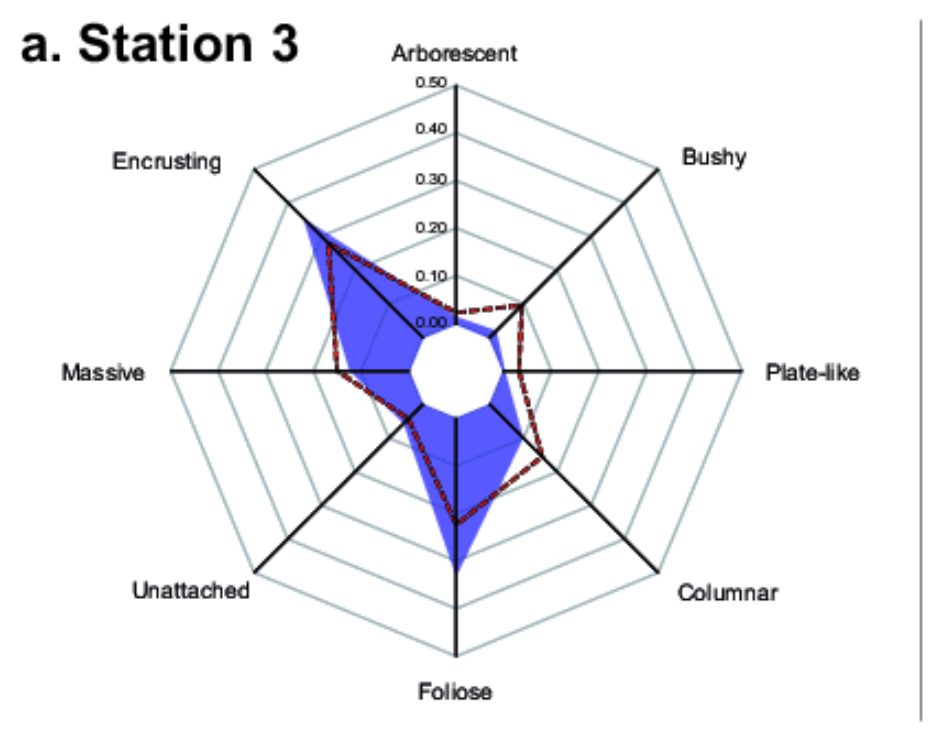

1. Massive: Massive / Submassive / Hemipherical (Phacelloid and Flabello-meandroid) corals 2. Encrusing: Encrusing corals

3. Foliose: Foliose/Laminar corals

4. Columnar: Columner corals

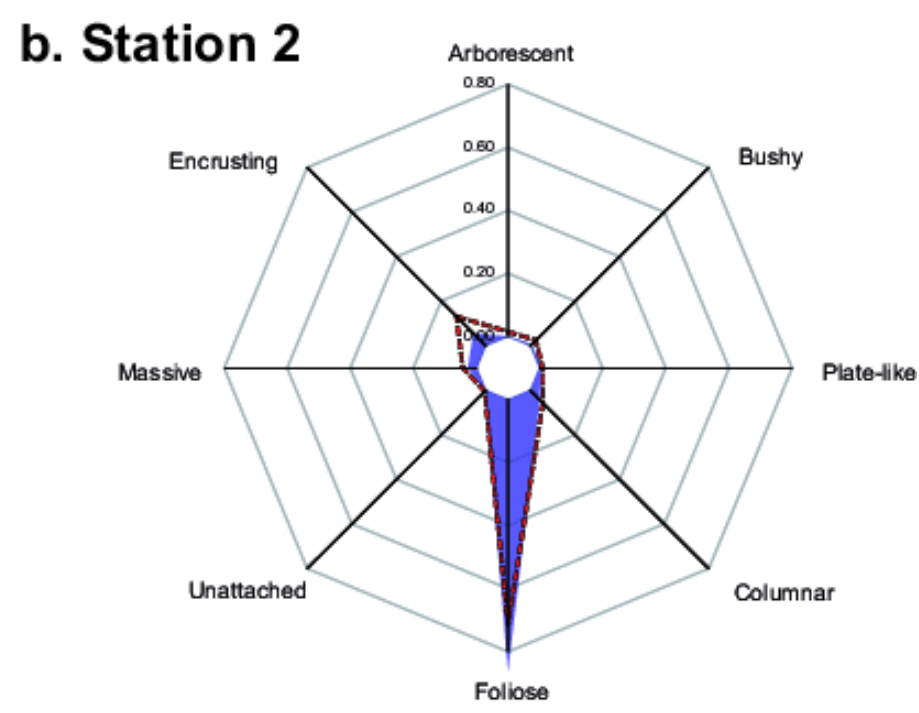

5. Plate-ike: Tabular corals

6. Bushy: Corymbose, Hispidose, Thickets

7. Arborescent: Staghom corals

8. Unattached: Free Iving corals

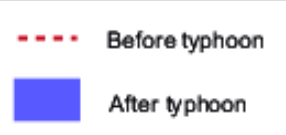
After typhoon 


\section{Table $\mathbf{1}_{\text {(on next page) }}$}

Stations at Ryugu Reef

Stations at Ryugu Reef

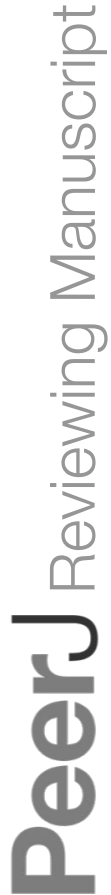




\begin{tabular}{lll}
\hline Station & Location/Description & Depth (m) \\
\hline \hline 1 & Outside outer edge of dense Pachyseris foliosa area, sandy & 42 \\
2 & Upper edge of dense Pachyseris foliosa area & 31.2 \\
3 & Upper edge of high diversity area & 26.5 \\
4 & Upper edge of Fungiidae/rubble area & 21.3 \\
5 & Sand, coral rubble & 17 \\
\hline
\end{tabular}

